\title{
МОДЕЛЬ ЦИФРОВОЙ ЗРЕЛОСТИ БАНКОВСКИХ ОРГАНИЗАЦИЙ
}

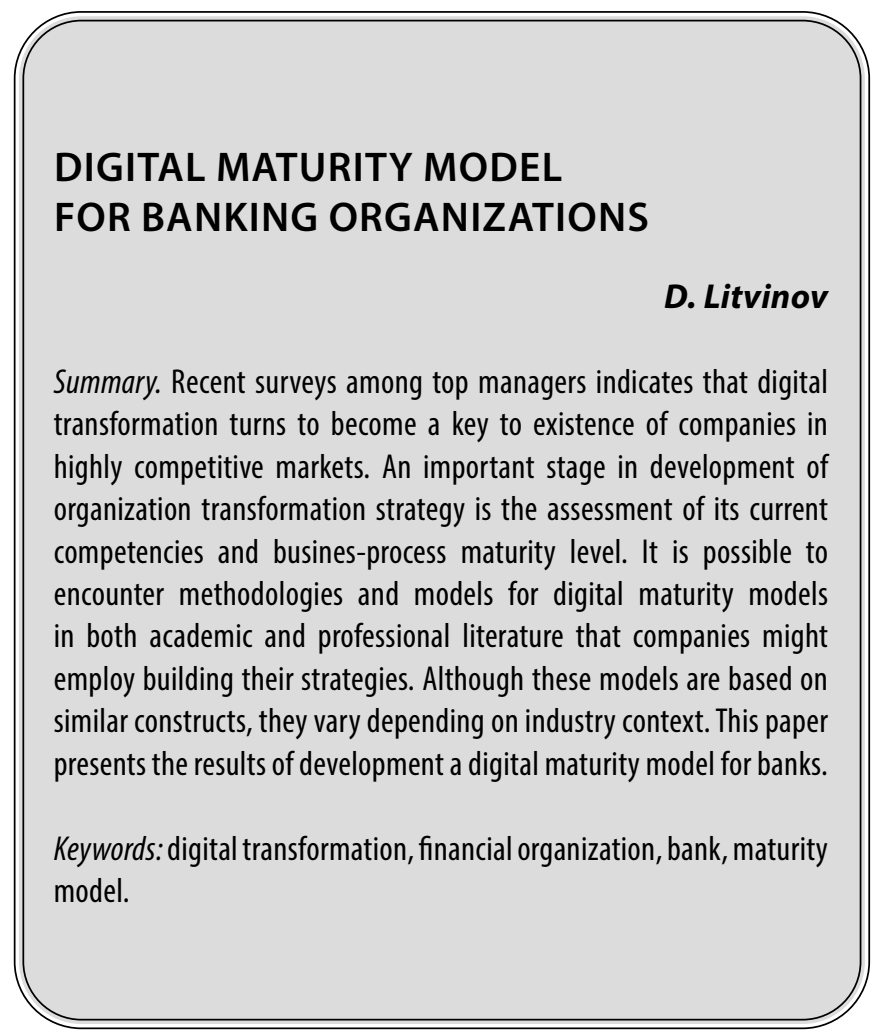

$\mathbf{P}$ яд исследований среди топ-менеджеров компаний по всему миру указывает на то, что цифровая трансформация становится ключом к выживанию организаций в будущем. Более половины руководителей считают, что скорость появления и внедрения инноваций возрастает, и основной причиной этому является появление новых цифровых технологий. Организации с устаревшей инфраструктурой, классической корпоративной культурой и иерархической структурой начинают уступать зародившимся в «цифровой век» конкурентам $[11 ; 5]$. Примеры успешных цифровых организаций представлены уже во всех значимых секторах экономики: финансовом, производственном, логистическом и государственном, - и именно они мотивируют остальных адаптировать свои стратегии и закладывать в них внедрение новых цифровых технологий в бизнес-процессы $[4 ; 12]$.

Важным этапом в формировании стратегии трансформации организации является оценка текущего состояния компетенций и бизнес-процессов [13]. В научной и профессиональной литературе можно найти примеры методик и моделей оценки цифровой зрелости организаций, которые компании могут использовать при разработке стратегии. Хотя в основе этих моделей можно

\author{
Литвинов Дмитрий Михайлович \\ Аспирант, Российский Экономический Университет \\ им. Г.В. Плеханова \\ litvinovdmm@yandex.ru
}

Аннотация. Ряд исследований среди топ-менеджеров компаний указывает на то, что цифровая трансформация становится ключом к выживанию организаций на высококонкурентных рынках. Важным этапом в формировании стратегии трансформации организации является оценка текущего уровня зрелости компетенций и бизнес-процессов. В научной и профессиональной литературе можно найти примеры методик и моделей оценки цифровой зрелости организаций, которые компании могут использовать при разработке стратегии. Хотя в основе этих моделей можно увидеть схожие элементы, они отличаются в зависимости от отраслевого контекста. В работе представлены результаты разработки модели оценки цифровой зрелости для банков.

Ключевые слова: цифровая трансформация, финансовая организация, банк, уровень зрелости.

увидеть схожие элементы, они отличаются в зависимости от отраслевого контекста.

Целью данной работы является разработка модели оценки цифровой зрелости для банковских организаций на базе анализа имеющейся литературы. Подход к отбору литературы для анализа, результаты обработки релевантных работ и предлагаемая для дальнейшего исследования модель будут описаны в следующих разделах. В заключении рассматриваются дальнейшие направления работы.

\section{Обзор литературы}

В рамках данной работы были проанализированы академические статьи и отчеты консалтинговых компаний. В качестве источников для поиска релевантных работ использовались поисковые системы google.com, scholar.google.com, elibrary.ru и сyberleninka.ru. Поисковые запросы содержали комбинации ключевых слов: «цифровая трансформация», «модель зрелости», «цифровые технологии».

Для дальнейшего анализа были отобраны следующие модели: модель цифровой зрелости телекоммуни- 

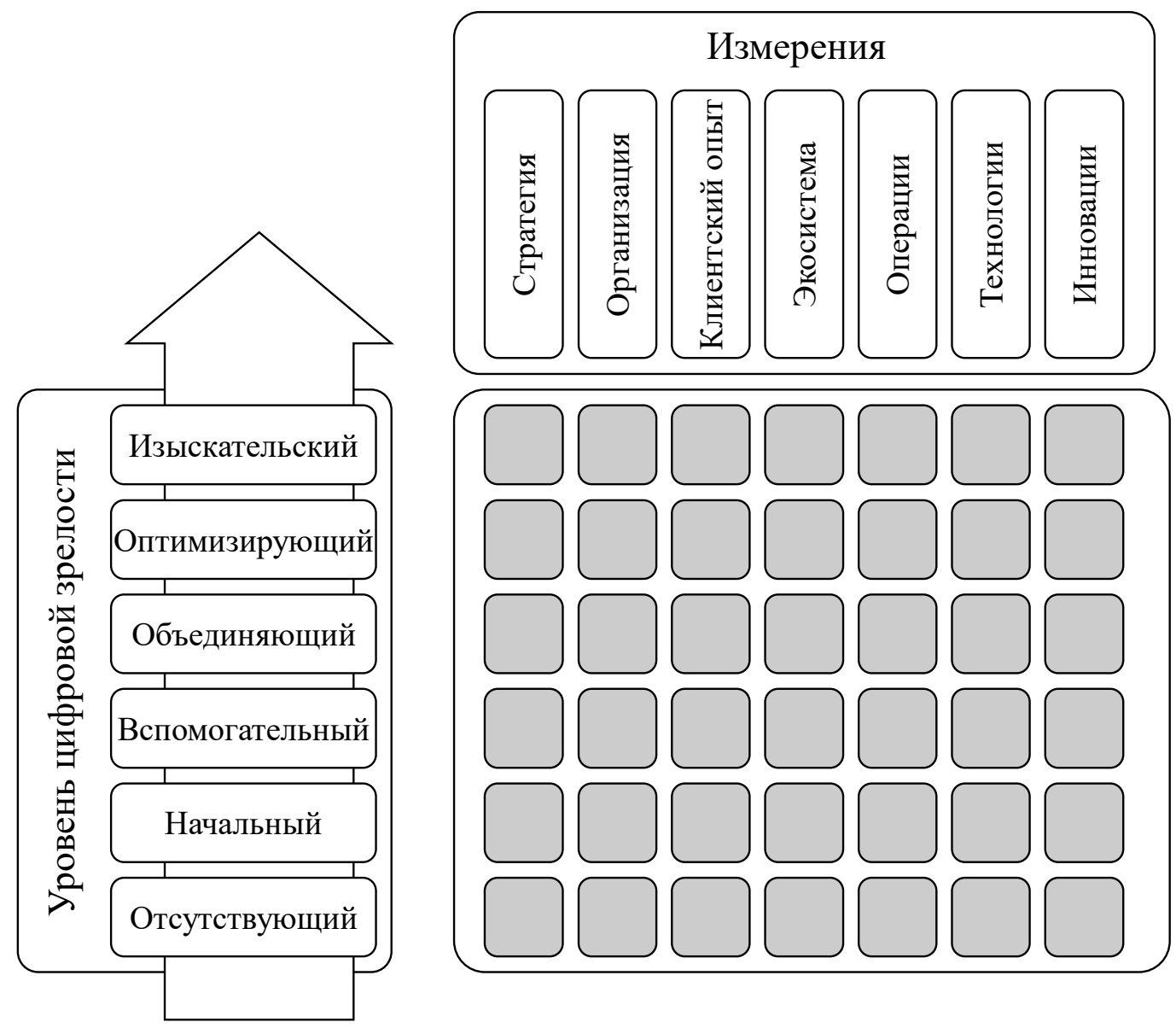

Рис. 1. Модель цифровой зрелости для телекоммуникационных компаний

кационных организаций $[14$, с. 21], модель цифровой зрелости производственных предприятий [10, с. 162], модель зрелости цифрового правительства [8].

В основе проанализированных моделей лежат классические модели зрелости и подходы к организационному развитию, такие как Модель Зрелости Возможностей (Capability Maturity Model) или Модель зрелости управления ИТ-сервисами (IT Service Management). В моделях используется классические 5 уровней зрелости: начальный, базовый, развивающийся, управляемый, оптимизирующий. Модели отличаются измерениями, которые являются специфичными для бизнес-доменов.

Далее будет рассмотрена каждая модель в отдельности.

\section{Молель шифровой зрелости те^екоммуникационных компаний}

Омар Вальдез-де-Леон предложил модель для телекоммуникационных компаний, которая включает в себя семь измерений: стратегия, организация, клиентский опыт, экосистема, операции, технологии и инновации $[14$, c. 29].

Стратегия включает в себя видение, управление и принципы принятия решений, которые обеспечивают исполнение цифровой стратегии. Под организацией в модели понимается изменения в корпоративной культуре, организационной структуре и системе управления знаниями, которые позволяют организации перейти в категорию цифровых. Клиентский опыт отражает набор улучшений в клиентских путях за счет внедрения цифровых технологий. Развитие взаимоотношений с партнерами и создание общей площадки для предоставления продуктов рассматривается как одно из ключевых измерений в модели и обозначается как экосистема. Следующее измерение в модели - операции. Операции представляют собой способность организации предоставлять клиентам услуги. Увеличение зрелости в этой области находит отражение в большей цифровизации, автоматизации и гибкости рутинных процессов. Технологии включают в себя планирование по внедрению и использованию технологических решений, которые обеспечивают цифровизацию бизнеса. Последнее изме- 


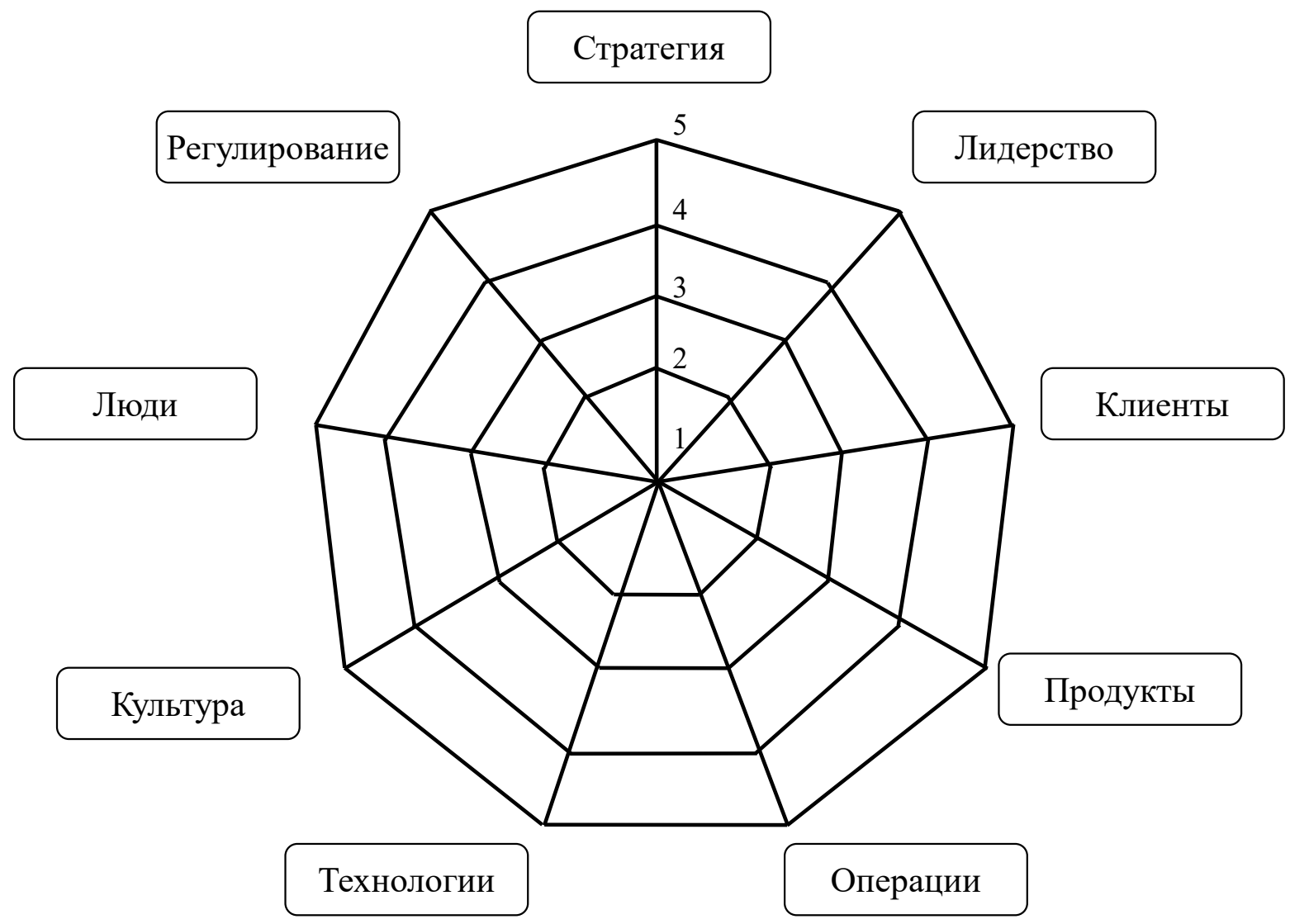

Рис. 2. Модель цифровой зрелости для производственных компаний

рение, инновации - это подходы к организации работы, которые позволяют гибко адаптироваться к изменяющемуся рынку и обеспечивают фундамент для развития цифровых сервисов [14, с. 20].

Для оценки зрелости организации в модели используется шкала, которая включает в себя следующие уровни: отсутствующий, начальный, вспомогательный, объединяющий, оптимизирующий, изыскательский. На уровне отсутствующий организация еще не предпринимала никаких шагов к цифровой трансформации. На начальном уровне компания приняла решение о необходимости изменять модель бизнеса с классической на цифровую и предприняла первые шаги в этом направлении. На вспомогательном уровне в организации уже реализуются инициативы, направленные на формирование основ для развития бизнеса по цифровой модели организации. Объединяющий уровень подразумевает интеграцию всех инициатив по трансформации в общий портфель, с целью получения сквозных цифровых процессов. На оптимизирующем уровне зрелости инициативы в рамках каждого измерения подлежат мониторингу и корректировке с целью повышения общей результативности цифровой организации. Изыскательский уровень зрелости представляет собой наивысший уровень, на котором организация становится пионером и создает новые практики на уровне каждого отдельного измерения.

Модель разрабатывалась на основе ранее опубликованных исследований и была валидирована с помощью метода «Дельфи». Для валидации модели были привлечены десять экспертов. В экспертную группу вошли как представители менеджеров высшего звена крупных поставщиков телекоммуникационных услуг, так и исследователи из академической среды, фокусирующиеся на анализе компаний телекоммуникационного сектора.

\section{Молель шифровой зрелости произво ственных преАприятий}

Шумахер и другие разработали модель цифровой зрелости для организаций, специализирующихся на промышленном производстве [10, с. 165]. Авторы выделили девять измерений, которые отражают ключевые области, влияющие на переход организации к цифровой модели ведения бизнеса: стратегия, лидерство, клиенты, продукты, операции, технологии, культура, люди и регулирование. 

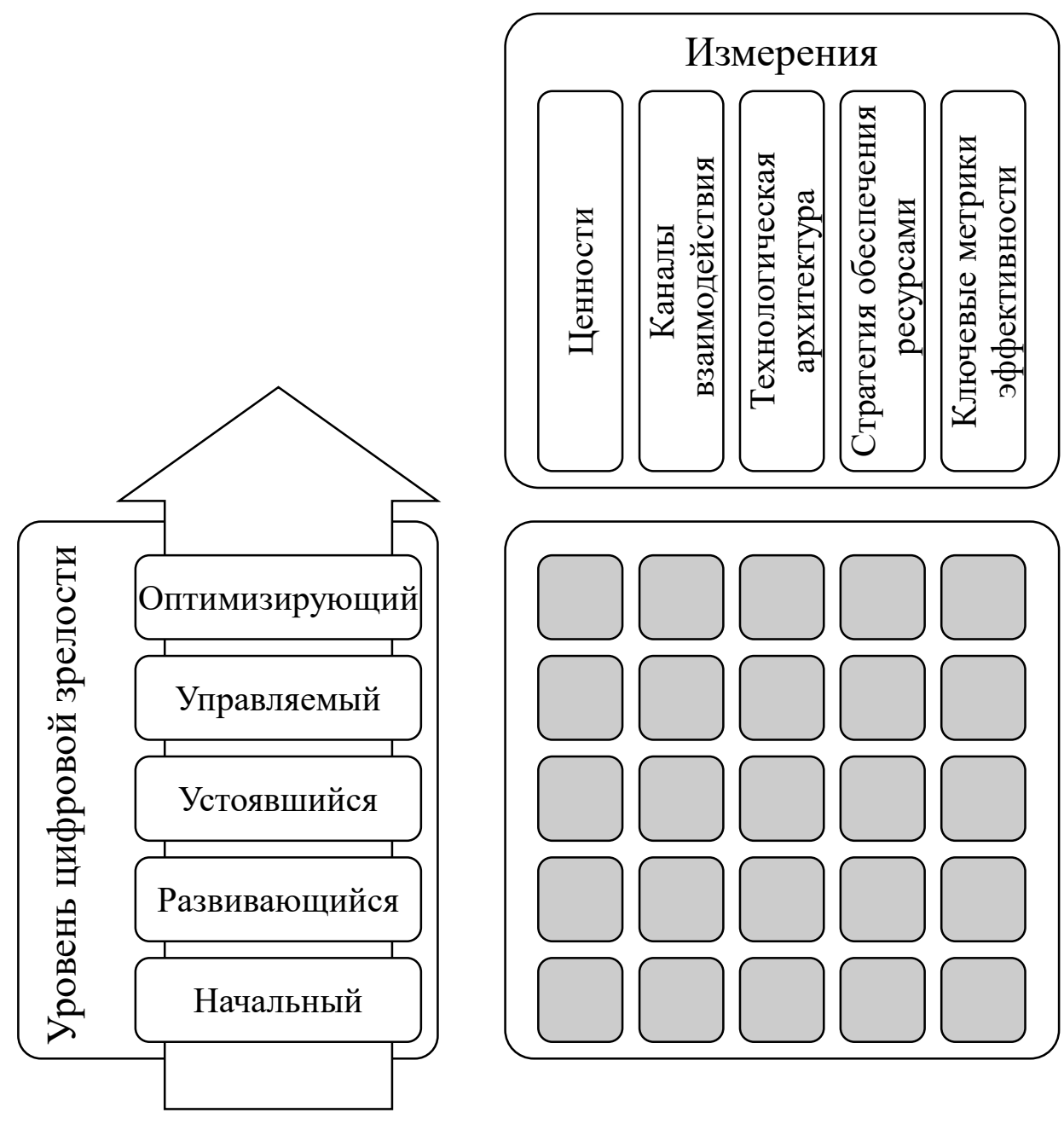

Рис. 3. Модель цифровой зрелости правительства

Для оценки зрелости исследовательская команда предложила оценивать каждое измерение по наличию или отсутствие характерных атрибутов. Так, например, для стратегии авторы выделили пять характерных признаков цифровой зрелости: использование дорожной карты по переходу к концепции Индустрии 4.0; наличие ресурсов, необходимых для реализации стратегических цифровых инициатив; коммуникация и документирование активностей в рамках перехода к Индустрии 4.0; возможность цифровизации бизнес-модели; наличие стратегии для цифровой трансформации и её соответствие Индустрии 4.0. Каждый отдельный атрибут оценивается по шкале Лайкерта [7, с. 229] от 1 - совершенно не характерен, до 5 - очень характерен.

Разработка модели проводилась аналогично модели для телекоммуникационных компаний на основе обширного анализа имеющейся литературы с последующей валидацией полученных результатов группой экспертов как из академической, так и производственной областей.

\section{Моцель шифровой зрелости правительства}

Мехлинг и другие представили в своем исследовании модель цифровой зрелости для государственных органов [8]. В рассматриваемой модели предлагается следующий набор характерных признаков цифровизации организации: изменения в ценностях, в стратегии каналов взаимодействия с потребителями услуг, в технологической архитектуре, в стратегии обеспечения ресурсами, в ключевых метриках эффективности. В качестве шкалы зрелости используется классическая шкала зрелости процессов СMMI [15] и включает в себя следующие уровни: начальный, развивающийся, устоявшийся, управляемый, оптимизирующий.

При переходе правительственной организации от начального уровня к оптимизирующему происходит смещение акцента в ценностях от эффективности и продуктивности к устойчивому развитию, автоматизация процессов приводит к обесцениванию существующих 
Таблица 1. Процедура разработки модели цифровой зрелости для банков. Модель 1 - модель цифровой зрелости для телекоммуникационных моделей, модель 2 - модель цифровой зрелости

для производственных компаний, модель 3 - модель цифровой зрелости для правительств.

\begin{tabular}{|c|c|c|c|}
\hline Модель 1 & Модель 2 & Модель 3 & Результирующая модель \\
\hline Стратегия & Стратегия & Стратегия обеспечения ресурсами & Стратегия \\
\hline Экосистема & - & Каналы взаимодействия & \multirow{2}{*}{ Экосистема } \\
\hline- & Продукты & & \\
\hline Клиентский опыт & Клиенты & - & Клиентские пути \\
\hline- & Люди & - & \multirow{6}{*}{ Организация } \\
\hline Культура & - & Ценности & \\
\hline Лидерство & Лидерство & & \\
\hline Организация & \multirow{2}{*}{ Организация } & \multirow{2}{*}{ - } & \\
\hline Инновации & & & \\
\hline- & - & Ключевые метрики эффективности & \\
\hline Операции & Операции & - & Операции \\
\hline Технологии & Технологии & Технологическая архитектура & Технологии \\
\hline- & Регулирование & - & Регулирование \\
\hline
\end{tabular}

омниканальных порталов, роль СІО трансформируется и включает в себя новые компетенции, технологическая архитектура трансформируется от состояния набора сервисов к глубоко интегрированному ландшафту машин с искусственным интеллектом, организация фокусируется на аутсорсинге технологических компетенцией, доля онлайн-услуг перестает быть ключевым показателем, а целью ставится максимальная автоматизация и снижение количества предоставляемых услуг, в которых требуется участие человека.

С целью формирования модели зрелости для банковских организаций используем метод синтеза [3], применив его к трем ранее рассмотренным моделям. Процедура выявления общих для всех моделей измерений представлена в Таблице 1.

На первом шаге для выявления общих характеристик моделей для различных бизнес-доменов было выполнено сопоставление измерений с учетом их определений. Схожие измерения были сгруппированы. Далее были выбраны только измерения, которые встречаются в двух из трех моделей. В результате был сформирован следующий набор параметров разрабатываемой модели: стратегия, экосистема, клиентские пути, организация, операции, технологии и регулирование.

Регулирование выделено в отдельное измерение только в модели оценки цифровой зрелости для производственных компаний, но включено в результирующую модель для банковских организаций ввиду высокого уровня влияния государственных органов на финансовую отрасль и применяемые в работе инструменты и технологии в зависимости от конкретной страны.
В предлагаемой модели для банков уровень цифровой зрелости декомпозируется на следующие измерения: стратегия, экосистема, клиентские пути, организация, операции и технологии. При этом организация представляет из себя составную компоненту, которая включает в себя следующие измерения: культура и лидерство. Предлагаемая структура модели представлена на рисунке 4.

Для дальнейшего исследования необходимо определить каждое из измерений и шкалу для их оценки.

\section{Стратегия}

Стратегия в рамках предлагаемой модели понимается как совокупность целей, планов, и средств достижения необходимых для цифровой трансформации. Данное определение отражает общепринятое определение стратегии с фокусом на исследуемую бизнес-область [6].

\section{Экосистема}

В 1996 году Джеймс Мур ввел понятие экосистемы бизнеса, которое расширяет границы исследования организаций, указывая на то, что в современных экономических отношениях существуют значимые связи между всеми контрагентами: акционеры, конкуренты, партнеры, профсоюзы, клиенты и т.д. В соответствии с этим определением в рамках данной работы экосистема определяется как альбом предлагаемых клиентам сервисов, спектр которых может расширяться как за счет партнерств, так и за счет развития нетипичных для основного бизнеса направлений. 


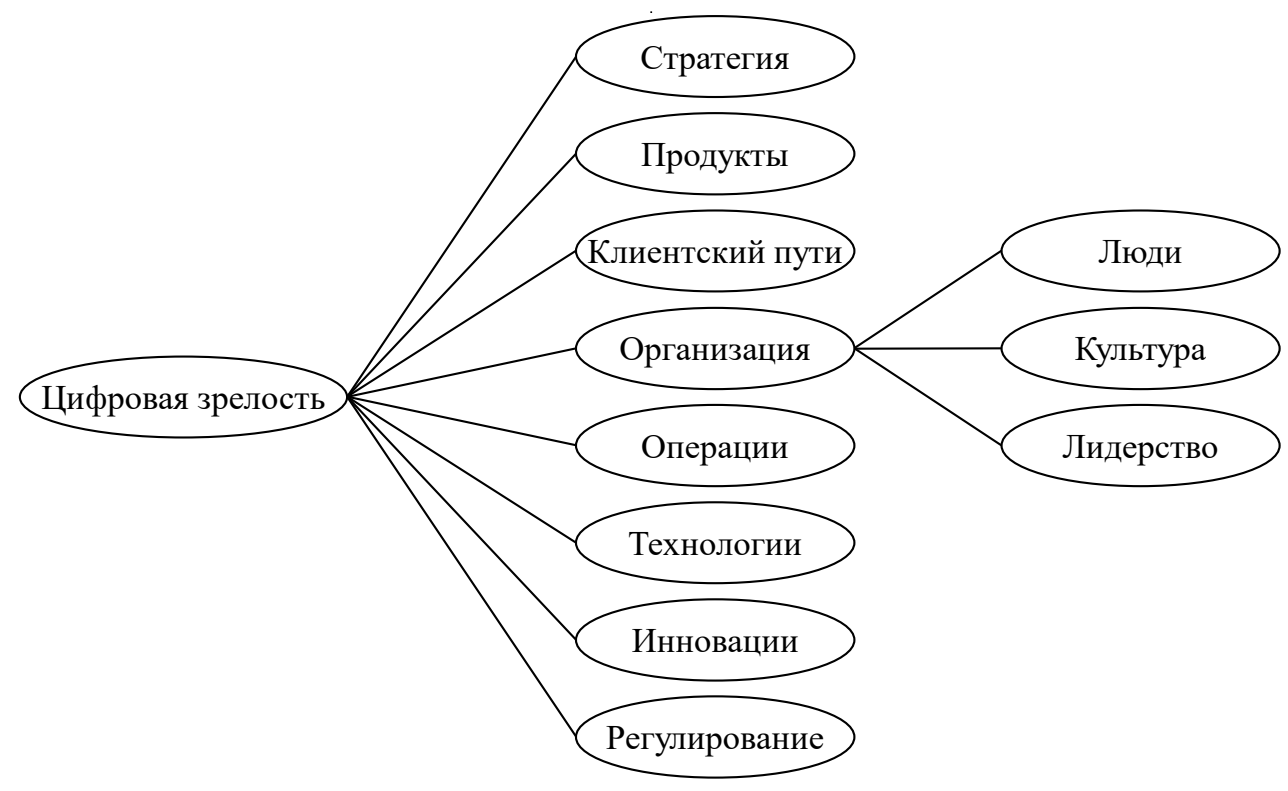

Рис. 4. Модель цифровой зрелости банковских организаций

\section{Клиентские пути}

Пайн и Гилмор предложили концепцию приобретения клиентами не товаров и услуг, а персонального опыта, который формируют компании на каждом этапе взаимодействия [9]. Данный подход подчеркивает, что именно клиентский путь, который проходит клиент от первой мысли об услуги до момента прекращения ее использования. В контексте модели клиентские пути рассматриваются как совокупность процессов, которые позволяют банку предоставлять услуги в наиболее удобном и подходящем клиенту формате.

\section{Организашия}

Организационная трансформация предполагает изменение подходов к принятию решений, управлению, необходимым компетенциям и ценностям, которые культивируются внутри банка. В ряде исследований отмечается, что именно наличие компетенций и изменение управленческого мышления являются пререквизитами для цифровизации компании [2; 1]. В рамках модели понятие организации декомпозируется на людей, культуру и лидерство, которые в свою очередь отражают уровень компетенций, подходы к принятию решений и управлению в организации и наличие ролей и людей, которые смогут инициировать изменения в рамках перехода к новой бизнес-модели.

\section{Операции}

В то время как клиентские пути определяют взаимодействие банка с клиентом, операции описывают вну- тренние процессы организации. Скорость выполнения, количество ошибок и объем выполняемых операций определяется сложностью внутренних регламентов и уровнем автоматизации. В рассматриваемой модели уровень цифровой зрелости организации отражается во внутренних операциях через глубину проникновения цифровых технологий в процессы, поддерживающие работу организации и предоставление услуг клиентам.

\section{Технологии}

В контексте разработанной модели способность финансовой организации к поиску областей применения цифровых технологий и наличие компетенций для их внедрения будет напрямую определять ее уровень цифровой зрелости.

\section{Регулирование}

В силу высокого уровня регулирования банковской отрасли со стороны государства в рамках модели регулирование отражает степень влияния надзорных органов на возможность применения цифровых технологий посредствам законодательства.

\section{Шкала измерения}

В качестве шкалы оценки каждого измерения будет использоваться адаптированная шкала модели СMМІ со следующими уровнями: начальный, развивающийся, устоявшийся, управляемый, оптимизирующий. Описание каждого уровня представлено в Таблице 2. 
Таблица 2. Шкала измерения уровня цифровой зрелости

\begin{tabular}{|c|c|}
\hline Уровень & Описание \\
\hline Начальный & $\begin{array}{l}\text { Инициировано изменение подходов и процессов с целью цифровой трансформации } \\
\text { организации }\end{array}$ \\
\hline Развивающийся & $\begin{array}{l}\text { Отдельные подходы и процессы изменяются за счет внедрения цифровых технологий новых } \\
\text { методологий }\end{array}$ \\
\hline Устоявшийся & $\begin{array}{l}\text { Разработаны планы по изменению подходов и процессов с целью цифровой трансформации } \\
\text { организации }\end{array}$ \\
\hline Управляемый & Определены целевые показатели для подходов и процессов и методы их измерения \\
\hline
\end{tabular}

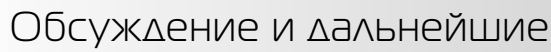
направления исслеАования

В данной работе представлены результаты по разработке модели цифровой зрелости и определение ее ключевых составляющих. Обзор литературы показал, что несмотря на наличие моделей цифровой зрелости для компаний различных отраслей, специ- фичной модели зрелости для банков ранее на разрабатывалось.

Следующим шагом в исследовании планируется разработать инструмент для проведения обследования уровня цифровой зрелости, в соответствии с разработанной моделью, и проведение оценки уровня зрелости одного из крупных российских банков.

\section{ЛИТЕРАТУРА}

1. Гилева Т.А., Компетенции и навыки цифровой экономики: разработка программы развития персонала // Вестник УГНТУ. Наука, образование, экономика. Серия: Экономика. 2019. № 2(28)

2. Кузин Д.М., Проблемы цифровой зрелости в современном бизнесе // Мир новой экономики. 2019. № 3

3. Новиков А.М. and Д.А. Новиков Методология научного исследования. 2010, Москва: Либроком

4. Сбербанк Стратегия развития Сбербанка 2018-2020. https://www.sberbank.com/common/img/uploaded/files/sberbankdevelopmentstrategyf or2018-2020.pdf. дата обращения 17.05.2020

5. Accenture The Post-Digital Era is Upon Us Are You Ready For What's Next? https://www.accenture.com/_acnmedia/pdf-94/accenture-techvision-2019-techtrends-report.pdf. дата обращения 17.05.2020

6. Freedman L., Strategy: A History. 2015: 0xford University Press

7. Likert, R., S. Roslow, and G. Murphy, A Simple and Reliable Method of Scoring the Thurstone Attitude Scales // The Journal of Social Psychology. 1934. № 5(2).

8. Mechling J., A. Di Maio and R. Howard Digital Government Is a Journey Toward Digital Business. 2014. Gartner

9. Pine B.J., et al., The Experience Economy: Work is Theatre \& Every Business a Stage. 1999: Harvard Business School Press.

10. Schumacher A., S. Erol, and W. Sihn, A Maturity Model for Assessing Industry 4.0 Readiness and Maturity of Manufacturing Enterprises // Procedia CIRP. 2016. № 52.

11. Tabrizi B., et al., Digital transformation is not about technology. https://hbr.org/2019/03/digital-transformation-is-not-about-technology. дата 06ращения 17.05.2020.

12. Toyota Annual report 2017: Long-term strategy. https://www.toyota-global.com/pages/contents/investors/ir_library/annual/pdf/2017/ar17_2_en.pdf._ дата обращения 17.05 .2020

13. Uhl A. and L.A. Gollenia A Handbook of Business Transformation Management Methodology. 2012, Farnham, United Kingdom: Gower Publishing

14. Valdez-de-Leon 0., A Digital Maturity Model for Telecommunications Service Providers // Technology Innovation Management Review. 2016. № 6(8).

15. CMMI Product Team, CMMI for Services v. 2.0. https://cmmiinstitute.com/cmmi. дата обращения 17.05.2020. 